\title{
BMJ Open Potentially avoidable hospitalisations of German nursing home patients? A cross-sectional study on utilisation patterns and potential consequences for healthcare
}

\author{
Rüdiger Leutgeb, Sarah Jane Berger, Joachim Szecsenyi, Gunter Laux
}

To cite: Leutgeb R, Berger SJ, Szecsenyi J, et al. Potentially avoidable hospitalisations of German nursing home patients? A cross-sectional study on utilisation patterns and potential consequences for healthcare. BMJ Open 2019;9:e025269. doi:10.1136/ bmjopen-2018-025269

- Prepublication history and additional material for this paper are available online. To view these files, please visit the journal online (http://dx.doi org/10.1136/bmjopen-2018025269).

Received 11 July 2018 Revised 17 October 2018 Accepted 12 December 2018

Check for updates

(C) Author(s) (or their employer(s)) 2019. Re-use permitted under CC BY-NC. No commercial re-use. See rights and permissions. Published by BMJ.

Department of General Practice and Health Services Research, University Hospital Heidelberg, Heidelberg, Germany

Correspondence to Dr Rüdiger Leutgeb; ruediger.leutgeb@med.uniheidelberg.de

\section{ABSTRACT}

Objectives Demand for nursing home (NH) care is soaring due to gains in life expectancy and people living longer with chronic illness and disability. This is dovetailing with workforce shortages across the healthcare profession. Access to timely and appropriate medical care for $\mathrm{NH}$ residents is becoming increasingly challenging and can result in potentially avoidable hospitalisations (PAHs). In light of these factors, we analysed PAHs comparing $\mathrm{NH}$ patients with non-NH patients.

Design Cross-sectional study with claims data from 2015 supplied by a large German health insurance company within the federal state of BadenWuerttemberg.

Setting One-year observation of hospitalisation patterns for $\mathrm{NH}$ and non-NH patients.

Participants 3872245 of the 10.5 million inhabitants of Baden-Wuerttemberg were covered.

Methods Patient data about hospitalisation date, sex, age, nationality, level of care and diagnoses were available. PAHs were defined based on international classification of diseases (ICD-10) diagnoses belonging to ambulatory care sensitive conditions (ACSCs). Adjusted ORs for PAHs for NH patients in comparison with non-NH patients were calculated with multivariable regression models.

Results Of the 933242 hospitalisations in 2015, there were 23982 for $13478 \mathrm{NH}$ patients and 909260 for 560998 non-NH patients. Mean age of hospitalised $\mathrm{NH}$ patients and level of care were significantly higher than those of non-NH patients. 6449 PAHs (29.6\%) for NH patients and 136543 PAHs (15.02\%) for nonNH patients were identified. The adjusted OR for PAHs was significantly heightened for $\mathrm{NH}$ patients in comparison with non-NH patients (OR: 1.22, $\mathrm{Cl}$ (1.18 to 1.26), $p<0.0001)$. Moreover, we could observe that more than $90 \%$ of PAHs with ACSCs were unplanned hospitalisations (UHs).

Conclusions Large numbers of PAHs for NH patients calls for improved coordination of medical care, especially general practitioner service provision. Introduction of targeted training programmes for physicians and NH staff on health problem management for $\mathrm{NH}$ patients could perhaps contribute to reduction of PAHs, predominantly UHs.
Strengths and limitations of this study

- The evaluation reports on a comprehensive sample of data of one year covering one whole federal state of Germany.

- This is the first study comparing potentially avoidable hospitalisations of nursing home residents with people living at home.

- It was possible to separate planned from unplanned hospitalisations.

- Our study design did not allow for remarks about sociodemographic data of the study population.

- Information on the staffing ratio or the education of the nursing home staff was not available to us.

\section{BACKGROUND}

Demand for nursing home $(\mathrm{NH})$ care is soaring due to gains in life expectancy and people living longer with chronic illness and disability. In Germany between 2013 and 2015 the number of nursing increased by $4.6 \%$. In 2015, $783000 \mathrm{NH}$ residents were observed. This is comparable with the situation in France. However, access to timely and appropriate medical care for $\mathrm{NH}$ residents is becoming increasingly challenging with frequency of home visits to NH residents rising in both regular and out-of-hours care (OOHC).${ }^{1-4}$ Provision of medical care to $\mathrm{NH}$ residents in Germany is predominantly provided by general practitioners (GPs), but this increasing demand for healthcare services is dovetailing with workforce shortages across the health professions including GPs. This is leading to gaps in care provision for $\mathrm{NH}$ residents and an increasing burden in terms of workload for GPs, especially in rural areas. ${ }^{45}$

This is exacerbated by a further problem in terms of the knowledge base and skill sets of nursing staff traditionally educated to work 
in German NHs (Altenpflege). Laws governing the curriculum, that is, required theoretical content and hours plus required clinical practice hours for the 3-year Altenpflege vocational nursing training, have not been updated since 2003, but in the subsequent 15 years, care needs of $\mathrm{NH}$ residents have become increasingly more complex as people live longer with chronic illness and comorbidities. ${ }^{6}$ There is a distinct need for upskilling and expansion of the roles and responsibilities of nursing staff working in German NHs. Workforce shortages in this occupational group, as well as lacking competencies, result in an increased burden to nurses and contribute to potentially avoidable hospitalisations (PAHs) ${ }^{7-9}$ Meanwhile, $\mathrm{NH}$ residents experience the consequences of these system issues at an individual level including discomfort to themselves, potentially increased risk of morbidity due to iatrogenic events, potential deterioration of dementia or delirious behaviours not to mention the financial implications related to PAHs. ${ }^{10}$

$\mathrm{NHs}$ residents have been associated with high rates of emergency department (ED) visits and a high rate of hospitalisations which is not just a problem in the German healthcare system. Several international studies point in the direction that a large number hospitalisations for $\mathrm{NH}$ residents are potentially avoidable. ${ }^{10-14}$ Common conditions of $\mathrm{NH}$ residents presenting to ED are pneumonia, falls with injuries, urinary tract infections, dehydration, partly as part of digestive problems often combined with pre-existing dementia. ${ }^{15-18}$ These all fall under the umbrella of 'ambulatory care sensitive conditions' (ACSCs), which in the ICD-10 codes include the most prevalent conditions for hospitalisations which could potentially be handled on an outpatient basis. ${ }^{19}$

The aim of this study was to identify PAHs of patients living in NHs and to compare these hospitalisations rates with the PAH rates of patients living at home. We distinguished between planned hospitalisations and unplanned hospitalisations (UHs). Our hypothesis was that the rate of PAHs from NHs and thereof the UHs would be significantly higher than of patients living at home.

\section{METHODS}

\section{Setting, design and participants}

Inpatient diagnoses of insured individuals living at home and of residents living in NHs supplied by the AOK ('Allgemeine OrtsKrankenkasse'), a statutory health insurance company within the Federal State Baden-Wuerttemberg were analysed in order to determine PAHs. All inpatient ICD-10 diagnoses in 2015 were screened for an established set of ACSCs compiled by health services researchers of the Department of General Practice and Health Services Research, University Hospital Heidelberg according to already published lists of ACSCs. ${ }^{19-21}$ The included conditions are shown in the online supplementary table 1.

Data were derived from a comprehensive evaluation programme in German primary care, the Hausarztzentrierte Versorgung $(\mathrm{HZV})$, loosely translated as 'family doctor coordinated care'. The HZV is a programme encouraging patients to enrol with a family doctor pursuant to Section 73b, Volume V of the German Social Security Law. It came into effect in Baden-Wuerttemberg on 1 July 2008. The HZV is aimed at enhancing healthcare for patients with chronic diseases and complex healthcare needs, for example, those requiring long-term care. ${ }^{22}$

In Germany, the rules for determining level of care for all patients depend on the severity of disease and multimorbidity. The level of care category assigned then determines the financial support available for continuous care from the healthcare insurance providers. ${ }^{23}$ Until 2016, patients could be categorised into one of four levels of care from 0 to 3 . These levels include assessed needs for both basic nursing care and specialised medical care. For example, patients who required basic nursing care of less than 0.75 hours per day were categorised in level 0 , patients who needed more than 4 hours basic nursing care per day and additionally required complex medical care were categorised in level 3. Since 2017, the level of care categories have been extended from 0 to 5 in order to include patients with incipient and advanced dementia who are otherwise physically healthy. ${ }^{24}$

The new outpatient models of care introduced by the National Health Service in England for patients with long-term conditions (LTCs) may be approximately comparable with the models of care in Germany. The five vital areas of LTCs described in these social models of care correspond to the items of level of care classification in Germany. The implementation of the models of care in daily routine are currently examined and evaluated in different vanguards spread across England. ${ }^{25-27}$

\section{Data}

The eligible study population consisted of 3.872 million individuals with statutory health insurance from AOK. The insurance claims data included diagnosis, date of hospitalisation, age, sex and nationality of the individuals. An UH could be identified in the forms of hospitalisation recorded in the available dataset by the health insurance company. Age, gender and nationality were available for every patient within the dataset. Based on the ICD-10, it was possible to determine the 'Charlson Index' in order to approximate patients' overall morbidity. There are particular diagnoses corresponding to more severe conditions. Values between 1 and 6 are assigned for those diagnoses. Finally, a sum score is determined for each individual. The underlying calculus is described in detail elsewhere. ${ }^{28}$

Data storage and extraction was performed with MySQL Community Server V.x64 (Oracle, Redwood Shores, California, USA).

\section{Statistical methods}

Multivariable analyses were performed with regard to patients' age, gender, nationality, morbidity and the binary variable for participation in the HZV intervention. 
Moreover, level of care for each patient in the multivariable model was included.

In order to calculate frequencies, rates and percentages we used SAS PROC SQL. In order to assess the adjusted outcomes of interest, we used SAS PROC GENMOD (SAS V.9.4×64, SAS Institute). ${ }^{29}$

For all analyses, results were considered statistically significant if the $\mathrm{p}$ value was 0.05 or less.

\section{Outcomes}

PAHs of individuals living at home and of individuals living in NHs were the primary outcome measures in this study. The comparison of planned hospitalisations and UHs was an additional outcome.

\section{Patient and public involvement}

Patients of the study could not be informed and involved because we used pseudonymised data. It was not possible to identify patients. The dissemination of the results will be performed by publicly accessible publications.

\section{RESULTS}

\section{Observed sample}

The sample drawn from the AOK statutory health insurance provider dataset included 13478 hospitalised patients from an overall population of $31079 \mathrm{NH}$ residents and 560998 hospitalised patients from an overall population of 3841166 AOK-insured persons living at home (table 1).

\section{Description of the included population}

Mean age of hospitalised patients living in NHs was $80.58 \pm 13.31$ years with significantly more women in this group than in the patient group living at home $(68.56 \%$ vs $53.64 \%)$. In comparison, the mean age of the hospitalised

\begin{tabular}{|c|c|c|c|}
\hline & \multicolumn{2}{|c|}{ Patients living } & \multirow[b]{2}{*}{$P$ value } \\
\hline & $\begin{array}{l}\text {...in nursing } \\
\text { Home }\end{array}$ & $\begin{array}{l}\text {... not in } \\
\text { nursing Home }\end{array}$ & \\
\hline Number of patients & 31079 & 3841166 & - \\
\hline $\begin{array}{l}\text { Number of } \\
\text { hospitalised } \\
\text { patients }\end{array}$ & 13478 & 560998 & - \\
\hline $\begin{array}{l}\text { Number of } \\
\text { admissions and } \\
\text { readmissions }\end{array}$ & 23982 & 909260 & - \\
\hline $\begin{array}{l}\text { Hospitalisation rate } \\
\text { (per } 100 \text { patients } \\
\text { per year) }\end{array}$ & 77.16 & 23.67 & $<0.0001$ \\
\hline PAHs (n, \%) & $6449(26.89)$ & $136543(15.02)$ & $<0.0001$ \\
\hline UHs (n, \%) & $\begin{array}{l}15647 \\
(65.24)\end{array}$ & 398167 (43.79) & $<0.0001$ \\
\hline
\end{tabular}

$\mathrm{PAH}$, potentially avoidable hospitalisation; $\mathrm{UH}$, unplanned hospitalisation.
Table 2 Demographics of hospitalised patients

\begin{tabular}{llll}
\hline & \multicolumn{2}{c}{ Patients living } & \\
\cline { 2 - 3 } & $\begin{array}{l}\text {...in nursing } \\
\text { home }\end{array}$ & $\begin{array}{l}\text {...not in } \\
\text { nursing home }\end{array}$ & P value \\
\hline $\begin{array}{l}\text { Number of patients } \\
13478\end{array}$ & 560998 & - \\
\hline $\begin{array}{l}\text { Age } \\
\text { (Average } \pm S D)\end{array}$ & $80.58 \pm 13.31$ & $55.52 \pm 24.66$ & $<0.0001$ \\
$\begin{array}{l}\text { Gender } \\
\text { (\% female) }\end{array}$ & 68.56 & 53.64 & $<0.0001$ \\
$\begin{array}{l}\text { Morbidity } \\
\text { (Average } \pm S D)\end{array}$ & $4.32 \pm 2.76$ & $2.23 \pm 2.65$ & $<0.0001$ \\
$\begin{array}{l}\text { Level of care } \\
\text { category } \\
\text { (AverageG } \pm S D)\end{array}$ & $1.82 \pm 0.76$ & $0.17 \pm 0.52$ & $<0.0001$ \\
$\begin{array}{l}\text { HZV enrolment } \\
\text { (\% participation) }\end{array}$ & $31.19 \%$ & $38.88 \%$ & $<0.0001$ \\
\hline
\end{tabular}

HZV, Hausarztzentrierte Versorgung.

patients living at home was $55.52 \pm 24.66$ years. Hospitalised $\mathrm{NH}$ patients suffered from more chronic diseases. In this study, level of care category for $\mathrm{NH}$ patients was significantly higher than for patients living at home ( $1.82 \pm 0.76$ vs $0.17 \pm 0.52$ ). HZV enrolment ('family doctor coordinated care') for hospitalised $\mathrm{NH}$ patients was somewhat lower than for hospitalised patients living at home (table 2).

\section{Hospitalisations patterns}

In total, 23982 hospitalisations of patients living in NHs and 909260 hospitalisations of patients living at home were evaluated for the 2015 period. This means a hospitalisation rate of $77.16 \%$ vs $23.67 \%$ in the two different study groups. A total of 15647 hospitalisations of the NH patients were either OOHC hospitalisations or hospitalisations due to an emergency (65.24\%). In comparison, 398167 of the 909260 hospitalisations of patients living at home were unplanned (43.79\%). This was a significantly higher proportion of UHs for NH residents in comparison with patients living at home (table 1).

\section{Comparison of ACSCs of NH patients and patients living at home}

A total of 6449 PAHs of $\mathrm{NH}$ patients (26.9\%) and 136543 PAHs of patients living at home $(15.02 \%)$ were identified. Comparing the two study populations, there was a significant increase in the relative rate $(79.03 \%)$ of ACSCs in the NH group. The adjusted ORs for patients living in NHs were significantly higher than the patient group living at home for PAHs as for UHs (table 3). This meant that the adjusted chance for a PAH was nearly $22 \%$ higher for patients living in an $\mathrm{NH}$ and the adjusted chance of UHs was more than $50 \%$ higher for patients living in an $\mathrm{NH}$ compared with patients living at home.

In addition, 90.87\% of PAHs with ACSCs were not in the category of planned hospitalisations. By implication, less than $10 \%$ of PAHs were planned hospitalisations. 
Table 3 Adjusted ORs for hospitalisation target variables, nursing home patients versus patients living at home

\begin{tabular}{llll}
\hline & OR & $\mathbf{9 5 \%} \mathbf{C l}$ & P value \\
\hline PAHs & 1.218 & $(1.179$ to 1.258$)$ & $<0.0001$ \\
UHs & 1.514 & $(1.470$ to 1.559$)$ & $<0.0001$ \\
\hline
\end{tabular}

$\mathrm{PAH}$, potentially avoidable hospitalisation; $\mathrm{UH}$, unplanned hospitalisation.

The top 10 PAHs according to ACSC category for both groups are shown in table 4. Pneumonia (J18), fracture of femur (S72), volume depletion (E86) and epilepsy (G40) occurred noticeably more often in $\mathrm{NH}$ patients.

\section{DISCUSSION}

The analysis of the AOK statutory health insurance provider dataset identified numerous PAHs especially in the context of UHs (including emergency and OOHC). A total of 23982 hospitalisations of NH patients and 909260 hospitalisations of patients living at home occurred in 2015. Comparing the number of PAHs in both patient groups, the adjusted ORs for PAHs were significantly higher in the $\mathrm{NH}$ group. More than $90 \%$ of PAHs in NHs with ACSCs were UHs. Our study design did not allow for remarks about sociodemographic data of the study population which could perhaps influence our results. In addition, information on the staffing ratio or the education of the NH staff was not available to us. With regard to the currently increasing workforce shortages in German NHs and the increasingly high workload of GPs, we consider that these could be key factors contributing to the significantly higher PAHs in NHs. ${ }^{630}$
Our results are in accordance with several other international studies which in particular identify the need for improved continuity of care for people in NHs. ${ }^{10} 12-1531$ Haber $e t a l^{2}$ showed in their study that consistency of the relationship between GP and $\mathrm{NH}$ patient was an important factor of reducing PAHs and of reducing OOHC or ED visits which often result in UHs. ${ }^{32}$ It is of great importance that the primary medical practitioners (usually GPs) know the medical history of their patients who are $\mathrm{NH}$ residents. This is for a number of reasons. First, to ensure optimal care management of patient health needs; second, to coordinate care between providers as well as to anticipate potential deterioration of patient health conditions and finally, to therefore reduce unnecessary utilisation of acute hospital services. ${ }^{1033}$

$\mathrm{NH}$ patients with ACSCs who do not have a primary healthcare provider in regular attendance will be potentially frequent attenders in OOHC and EDs. ${ }^{34} 35$ The overcrowding of OOHC centres and EDs is as well as PAHs (normally UHs) of NH patients are stretching resources to the limits in healthcare systems of many European countries and the USA. ${ }^{36}{ }^{37}$ Frequent attenders or patients with minor ailments are in large part responsible for the high workload of physicians and staff in OOHC and EDs. Consultations of these patients with perhaps minor ailments in OOHC or EDs should be avoided, except for the most urgent or complex cases. ${ }^{38-40}$ However, this is creating the need for new approaches to conditions such as pneumonia, falls risk (eg, to prevent fracture of femur), volume depletion and epilepsy which are four of the most frequent diagnoses connected with PAHs in our study and common problems in NHs. ${ }^{164142}$

Table 4 Top 10 PAHs according to ACSC category

\begin{tabular}{|c|c|c|c|c|c|c|c|c|c|}
\hline \multicolumn{5}{|c|}{ Nursing home patients } & \multicolumn{5}{|c|}{ Non-nursing home patients } \\
\hline Rank & $\begin{array}{l}\text { ICD-10 } \\
\text { code }\end{array}$ & Diagnosis & $\mathbf{n}$ & $\%$ & Rank & $\begin{array}{l}\text { ICD-10 } \\
\text { code }\end{array}$ & Diagnosis & $\mathbf{n}$ & $\%$ \\
\hline 2 & 150 & Heart failure & 1137 & 17.61 & 2 & $\mathrm{~F} 10$ & $\begin{array}{l}\text { Disorders due to use of } \\
\text { alcohol }\end{array}$ & 16204 & 11.86 \\
\hline 3 & S72 & Fracture of femur & 827 & 12.81 & 3 & J18 & Pneumonia & 12195 & 8.93 \\
\hline 5 & G40 & Epilepsy & 549 & 8.50 & 5 & 110 & $\begin{array}{l}\text { Essential (primary) } \\
\text { hypertension }\end{array}$ & 9574 & 7.01 \\
\hline 6 & E11 & $\begin{array}{l}\text { Type } 2 \text { diabetes } \\
\text { mellitus }\end{array}$ & 332 & 5.14 & 6 & $\mathrm{~S} 72$ & Fracture of femur & 6868 & 5.03 \\
\hline 7 & $\mathrm{~J} 20$ & Acute bronchitis & 278 & 4.31 & 7 & E11 & Type 2 diabetes mellitus & 6262 & 4.58 \\
\hline 10 & K59 & $\begin{array}{l}\text { Other functional } \\
\text { intestinal disorders }\end{array}$ & 120 & 1.86 & 10 & E86 & Volume depletion & 4434 & 3.25 \\
\hline
\end{tabular}

ACSC, ambulatory care sensitive condition PAH, potentially avoidable hospitalisation. 
There is little doubt on, a case-by-case basis, that such listed conditions may be severe diseases without the possibility of being treated in an outpatient setting but prophylactic and monitoring procedures for these conditions are possible and do not seem to be too complex in the first instance. However, individually tailored prophylactic and monitoring procedures for $\mathrm{NH}$ residents are resource intensive in terms of both time and staff and, due to resource constraints and workforce shortages, are a major cause of current deficiencies in care provision.

Considering the increasing shortages of GPs, especially in rural areas, as well as increasing shortages of appropriately trained NH staff, health policies and health services experts have to look for innovative approaches to ease the healthcare services crisis emerging in NHs. Therefore, additional measures to be pursued are that the education of NH staff should be reviewed and improved and nursing staff should be formally empowered to manage minor ailments for example, like fever and pain in the first instance. Unfortunately, government regulations in Germany currently prohibit in many cases independent clinical decisions of nursing staff in NHs. The daily work of nursing staff and medical practitioners is made difficult because of such regulations are no longer in keeping with the tensions and demands in clinical practice in these settings. ${ }^{434}$

In Germany, the current government has introduced a new workforce policy to address the pressing problem of staff shortages and agreed to fund 8000 new geriatric nurses (Altenpflege) with enhanced competencies for $\mathrm{NHs}$ through the statutory health insurance. ${ }^{30}$ The policy for upskilling a segment of the geriatric nursing workforce is one important step but will not bring immediate improvements to coordination of care and information flow between the different providers across healthcare sectors. PAHs of NH residents and effective outpatient management remain complex problems that must be dealt with in parallel on many fronts.

The complex difficulties in improving the care of $\mathrm{NH}$ residents were shown in the Interventions to reduce Acute Care Transfers programme-a randomised prospective study. Despite training and support of the staff, the objectives of reducing hospital admissions or $\mathrm{ED}$ visits for $\mathrm{NH}$ residents were not achieved. ${ }^{43}$ Kane at al explain the lack of effectiveness are being due to a multitude of interacting factors: quality of the NH staff, lacking continuous medical care, concerns over liability and poor motivation to reduce hospitalisations in $\mathrm{NH}$ patients. ${ }^{43}$

Perhaps in future service providers such as nurse practitioners, medical assistants-in Germany VERAH (Versorgungsassistentin in der Hausarztpraxis)—palliative care teams, geriatric specialist services may support primary care providers (GPs) and NH staff in improving medical care and reducing PAHs of nursing home residents. ${ }^{10}{ }^{45-47}$ However, the proven effects of these new models or interventions remains low and should be studied further. ${ }^{47}$
A further initiative by the German government has been the introduction of the 'Innovation Fund'. With this programme, health services research projects are subsidised, and this includes among others, pilot projects to improve the care of $\mathrm{NH}$ residents and to reduce PAHs. It remains to be seen if the results of these projects translate to improved responsiveness to the needs of $\mathrm{NH}$ residents. ${ }^{48-50}$

Finally, the issue of remuneration needs to be addressed. High workloads, dealing with the impacts of staff shortages and increasingly complex patient care requirements in the primary care sector, place a burden on the existing workforce. GPs, other specialists and nursing staff should also be remunerated adequately and advanced training to upskill staff should be incentivised. In that respect, NHs, insurance companies and the government are called on to give financial incentives. ${ }^{4105152}$

\section{CONCLUSIONS}

A high rate of PAHs, which may be predominantly UHs (OOHC/ED) for NH residents, could suggest that the traditional approach to healthcare provision in $\mathrm{NHs}$ needs improvement. At the individual level, physicians in primary care and OOHC and the staff in NHs have to be sensitised to manage common health problems of patients that too often result in PAHs. There is little doubt that the management of diseases with ACSCs is a complex problem. These problems need case-by-case decisions, to determine whether they are best managed in outpatient or inpatient settings. We consider prerequisites for improved intersectoral collaboration are sufficient numbers of NH staff, upskilled with today's needed competencies and GPs/primary care medical specialists who are motivated to upskill in geriatric healthcare. Finally, at a system level, policy-makers and regulators of the health professions need to use incentives and remuneration programmes to achieve the ambitious goals of improving NH care and reducing PAHs-predominantly UHs-of NH residents.

Acknowledgements The data usage grant from the AOK Baden-Wuerttemberg for this study is greatly acknowledged. We additionally acknowledge financial support by DeutscheForschungsgemeinschaft within the funding programme Open Access Publishing, bythe Baden-Württemberg Ministry of Science, Research and the Arts and byRuprecht-Karls-Universität Heidelberg

Contributors GL, JS and RL initiated and designed the study. GL and RL coordinated the study. GL carried out data analysis. RL, SJB (native English speaker) and GL wrote the manuscript. All authors (RL, SJB, JS and GL) commented on the draft and approved the final version of the manuscript.

Funding The authors have not declared a specific grant for this research from any funding agency in the public, commercial or not-for-profit sectors.

Competing interests None declared.

Patient consent for publication Not required.

Ethics approval Ethical approval for the study was given by the University Hospital Heidelberg Ethics Committee (No. S-359/2013).

Provenance and peer review Not commissioned; externally peer reviewed.

Data sharing statement Data used in this analysis are not in the public domain and use is covered by data sharing agreements with the AOK Baden-Wuerttemberg. 
Open access This is an open access article distributed in accordance with the Creative Commons Attribution Non Commercial (CC BY-NC 4.0) license, which permits others to distribute, remix, adapt, build upon this work non-commercially, and license their derivative works on different terms, provided the original work is properly cited, appropriate credit is given, any changes made indicated, and the use is non-commercial. See: http://creativecommons.org/licenses/by-nc/4.0/.

\section{REFERENCES}

1. Pflegestatistik- Statistisches Bundesamt. Pflegebedürftige zum Jahresende 2015. 2015 https://www.destatis.de/DE/Publikationen/ Thematisch/Gesundheit/Pflege/PflegeDeutschlandergebnisse52240 01159004.pdf?_blob=publicationFile (Acessed on 06 Jul 2018).

2. Bedarfsgerechte Versorgung Sachverständigengutachten. 2014 http://www.svr-gesundheit.de/fileadmin/user_upload/Gutachten/ 2014/Zusammenfassung_GA_2014.pdf (Accessed 06 Jul 2018).

3. Atramont A, Bourdel-Marchasson I, Bonnet-Zamponi D, et al. Impact of nursing home admission on health care use and disease status elderly dependent people one year before and one year after skilled nursing home admission based on 2012-2013 SNIIRAM data. BMC Health Serv Res 2017;17:667.

4. Groom L, Avery AJ, Boot D, et al. The impact of nursing home patients on general practitioners' workload. $\mathrm{Br} J$ Gen Pract 2000;50:473-6.

5. McDermott C, Coppin R, Little P, et al. Hospital admissions from nursing homes: a qualitative study of GP decision making. British Journal of General Practice 2012;62:e538-45.

6. Bundesministerium für Familie, Senioren, Frauen und Jugend. Altenpflegegesetz des Bundes. https://www.altenpflegeausbildung. net/fachinformationen/altenpflegegesetz-des-bundes.html (Accessed 06 Jul 2018)

7. Bleckwenn M, Ashrafnia D, Schnakenberg R, et al. Urgent visits to nursing homes: a general practitioner's perspective. Gesundheitswesen 2017.

8. Bleckwenn M, Bell L, Schnakenberg R, et al. [Outpatient emergency care for nursing home residents: a status quo from a nursing perspective]. Gesundheitswesen. In Press. 2018.

9. Rommel A, Kottner J, Suhr R, et al. [Frequency of falls among clients of home care services: the importance of care-related and social risk factors]. Z Gerontol Geriatr. In Press. 2017.

10. Ouslander JG, Lamb G, Perloe M, et al. Potentially avoidable hospitalizations of nursing home residents: frequency, causes, and costs: [see editorial comments by Drs. Jean F. Wyman and William R. Hazzard, pp 760-761]. J Am Geriatr Soc 2010;58:627-35.

11. Grabowski DC, O'Malley AJ, Barhydt NR. The costs and potential savings associated with nursing home hospitalizations. Health Aff 2007;26:1753-61.

12. Walker JD, Teare GF, Hogan DB, et al. Identifying potentially avoidable hospital admissions from canadian long-term care facilities. Med Care 2009;47:250-4.

13. Wyman JF, Hazzard WR. Preventing avoidable hospitalizations of nursing home residents: a multipronged approach to a perennial problem. J Am Geriatr Soc 2010;58:760-1.

14. Van Rensbergen $G$, Nawrot T. Medical conditions of nursing home admissions. BMC Geriatr 2010;10:46.

15. Carron P-N, Mabire C, Yersin B, et al. Nursing home residents at the Emergency Department: a 6-year retrospective analysis in a Swiss academic hospital. Intern Emerg Med 2017;12:229-37.

16. Briggs R, Coughlan T, Collins R, et al. Nursing home residents attending the emergency department: clinical characteristics and outcomes. QJM 2013;106:803-8.

17. Carron PN, Mabire C, Yersin B, et al. Nursing home residents at the Emergency Department: a 6-year retrospective analysis in a Swiss academic hospital. Intern Emerg Med 2017;12:229-37.

18. Dwyer R, Gabbe B, Stoelwinder JU, et al. A systematic review of outcomes following emergency transfer to hospital for residents of aged care facilities. Age Ageing 2014;43:759-66.

19. Purdy S, Griffin T, Salisbury C, et al. Ambulatory care sensitive conditions: terminology and disease coding need to be more specific to aid policy makers and clinicians. Public Health 2009;123:169-73.

20. Freund T, Campbell SM, Geissler S, et al. Strategies for reducing potentially avoidable hospitalizations for ambulatory care-sensitive conditions. Ann Fam Med 2013;11:363-70.

21. Sundmacher L, Fischbach D, Schuettig W, et al. Which hospitalisations are ambulatory care-sensitive, to what degree, and how could the rates be reduced? Results of a group consensus study in Germany. Health Policy 2015;119:1415-23.

22. Laux G, Kaufmann-Kolle P, Bauer E, et al. [Evaluation of family doctor centred medical care based on AOK routine data in BadenWürttemberg]. Z Evid Fortbild Qual Gesundhwes 2013;107:372-8.
23. Bundesgesundheitsministerium. Online-Ratgeber Pflege. https:// www.bundesgesundheitsministerium.de/themen/pflege/onlineratgeber-pflege/pflegebeduerftigkeit.html (Accessed 06 Jul 2018).

24. Bundesgesundheitsministerium. Meldungen 2016-Neuregelungen. 2017 https://www.bundesgesundheitsministerium.de/ministerium/ meldungen/2016/neuregelungen-2017.html (Accessed 06 Jul 2018).

25. Goodwin N, Curry N, Naylor C, et al. Managing people with longterm conditions. https://www.kingsfund.org.uk/sites/default/files/ field/field_document/managing-people-long-term-conditions-gpinquiry-research-paper-mar11.pdf (Accessed 06 Jul 2018).

26. NHS. Next steps on the NHS five year forward view. https://www. england.nhs.uk/wp-content/uploads/2017/03/NEXT-STEPS-ON-TheNHS-five-year-forward-view.pdf (Accessed 06 Jul 2018)

27. Watson L. New models of care programme for PACs and MCPs. https://www.kingsfund.org.uk/sites/default/files/media/Louise Watson.pdf (Accessed 06 Jul 2018).

28. Sundararajan V, Henderson T, Perry C, et al. New ICD-10 version of the Charlson comorbidity index predicted in-hospital mortality. J Clin Epidemiol 2004;57:1288-94

29. PROC GENMOD Statement. SAS User's Guide. 2nd edn, 2018.

30. Koalitionsvertrag zwischen CDU, CSU und SPD 19. Legislaturperiode. 2018 https://www.bundesregierung.de/Content/ DE/_Anlagen/2018/03/2018-03-14-koalitionsvertrag.pdf (Accessed 06 Jul 2018).

31. Brownell J, Wang J, Smith A, et al. Trends in emergency department visits for ambulatory care sensitive conditions by elderly nursing home residents, 2001 to 2010. JAMA Intern Med 2014;174:156-8.

32. Haber SG, Wensky SG, McCall NT. Reducing inpatient hospital and emergency room utilization among nursing home residents. J Aging Health 2017;29:510-30.

33. Konetzka RT, Stearns SC, Park J. The staffing-outcomes relationship in nursing homes. Health Serv Res 2008;43:1025-42.

34. Buja A, Fusco M, Furlan P, et al. Referral patterns in elderly emergency department visits. Ann Ist Super Sanita 2013;49:395-401.

35. Lukin B, Fan LJ, Zhao JZ, et al. Emergency department use among patients from residential aged care facilities under a Hospital in the Nursing Home scheme in public hospitals in Queensland Australia. World J Emerg Med 2016;7:183-90.

36. Margolius D, Bodenheimer T. Redesigning after-hours primary care. Ann Intern Med 2011;155:131-2.

37. Majeed A. Redesigning after-hours primary care. Ann Intern Med 2012;156:67-8.

38. Leutgeb R, Engeser P, Berger S, et al. Out of hours care in Germany - High utilization by adult patients with minor ailments? BMC Fam Pract 2017;18:42.

39. Jacob R, Wong ML, Hayhurst $C$, et al. Designing services for frequent attenders to the emergency department: a characterisation of this population to inform service design. Clin Med 2016;16:325-9.

40. den Boer-Wolters D, Knol MJ, Smulders K, et al. Frequent attendance of primary care out-of-hours services in the Netherlands: characteristics of patients and presented morbidity. Fam Pract 2010;27:129-34.

41. Büchele G, Becker C, Cameron ID, et al. Predictors of serious consequences of falls in residential aged care: analysis of more than 70,000 falls from residents of Bavarian nursing homes. J Am Med Dir Assoc 2014;15:559-63.

42. Aymes S. Neurology advisor: epilepsy, seizures common among nursing home population. https://neurologyadvisor.com/epilepsy/ epilepsy-seizures-common-in-nursing-home-elderly/article/643330 (Accessed 06 Jul 2018)

43. Kane RL, Huckfeldt P, Tappen R, et al. Effects of an intervention to reduce hospitalizations from nursing homes: a randomized implementation trial of the INTERACT program. JAMA Intern Med 2017;177:1257-64.

44. McDermott C, Coppin R, Little P, et al. Hospital admissions from nursing homes: a qualitative study of GP decision making. $\mathrm{Br} J$ Gen Pract 2012;62:e538-45.

45. Kane RL, Keckhafer G, Flood S, et al. The effect of evercare on hospital use. J Am Geriatr Soc 2003;51:1427-34.

46. VERAH. VERAH (Versorgungsassistentin in der Hausarztpraxis). https://www.verah.de/ (Accessed 06 Jul 2018).

47. Graverholt B, Forsetlund L, Jamtvedt G. Reducing hospital admissions from nursing homes: a systematic review. BMC Health Serv Res 2014;14:36.

48. Bundesausschuss G. Erweiterte ärztliche Pflegeheimversorgung https://innovationsfonds.g-ba.de/projekte/neue-versorgungsformen/ cocare-coordinated-medical-care-erweiterte-koordinierte-aerztlichepflegeheimversorgung.70 (Accessed 06 Jul 2018).

49. Bundesausschuss G. Effekte von Strategien zur Verbesserung ärztlich-pflegerischer Zusammenarbeit auf Krankenhausaufnahmen von Pflegeheimbewohnern. https://innovationsfonds.g-ba.de/ 
projekte/versorgungsforschung/interprof-act-effekte-von-strategienzur-verbesserung-aerztlich-pflegerischer-zusammenarbeit-aufkrankenhausaufnahmen-von-pflegeheimbewohnern.62 (Accessed 06 Jul 2018).

50. Bundesausschuss G. Hospitalisierung und Notaufnahmebesuche von Pflegeheimbewohnern. Intervention zur Verbesserung der Versorgung. https://innovationsfonds.g-ba.de/projekte/ versorgungsforschung/homern-hospitalisierung-und- notaufnahmebesuche-von-pflegeheimbewohnern-haeufigkeitursachen-und-entwicklung-einer-intervention-zur-verbesserung-derversorgung.54 (Accessed 06 Jul 2018).

51. Gleeson LE, Jennings S, Gavin R, et al. Primary care in nursing homes revisited: survey of the experiences of primary care physicians. Ir Med J 2014;107:234-6.

52. Ashton T. Hospitalizations of nursing homes residents: the role of reimbursement policies. Isr J Health Policy Res 2014;3:3. 